
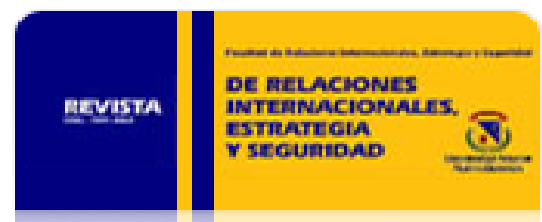

Revista de Relaciones Internacionales, Estrategia y Seguridad

ISSN: 1909-3063

cinuv.relinternal@unimilitar.edu.co

Universidad Militar Nueva Granada

Colombia

Niño, Jairo

RELACIONES INTERNACIONALES DE AMÉRICA LATINA. Lectura para la configuración de un sentido comunitario eficiente

Revista de Relaciones Internacionales, Estrategia y Seguridad, vol. 3, núm. 2, julio-diciembre, 2008,

pp. $59-89$

Universidad Militar Nueva Granada

Bogotá, Colombia

Disponible en: http://www.redalyc.org/articulo.oa?id=92712967004

Cómo citar el artículo

- Número completo

- Más información del artículo

Página de la revista en redalyc.org

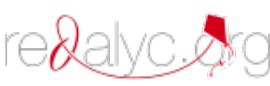

Sistema de Información Científica

Red de Revistas Científicas de América Latina, el Caribe, España y Portugal

Proyecto académico sin fines de lucro, desarrollado bajo la iniciativa de acceso abierto 
rev.relac.int.estrateg.segur.3(2):59-89,2008

\section{RELACIONES INTERNACIONALES DE AMÉRICA LATINA. Lectura para la configuración de un sentido comunitario eficiente*}

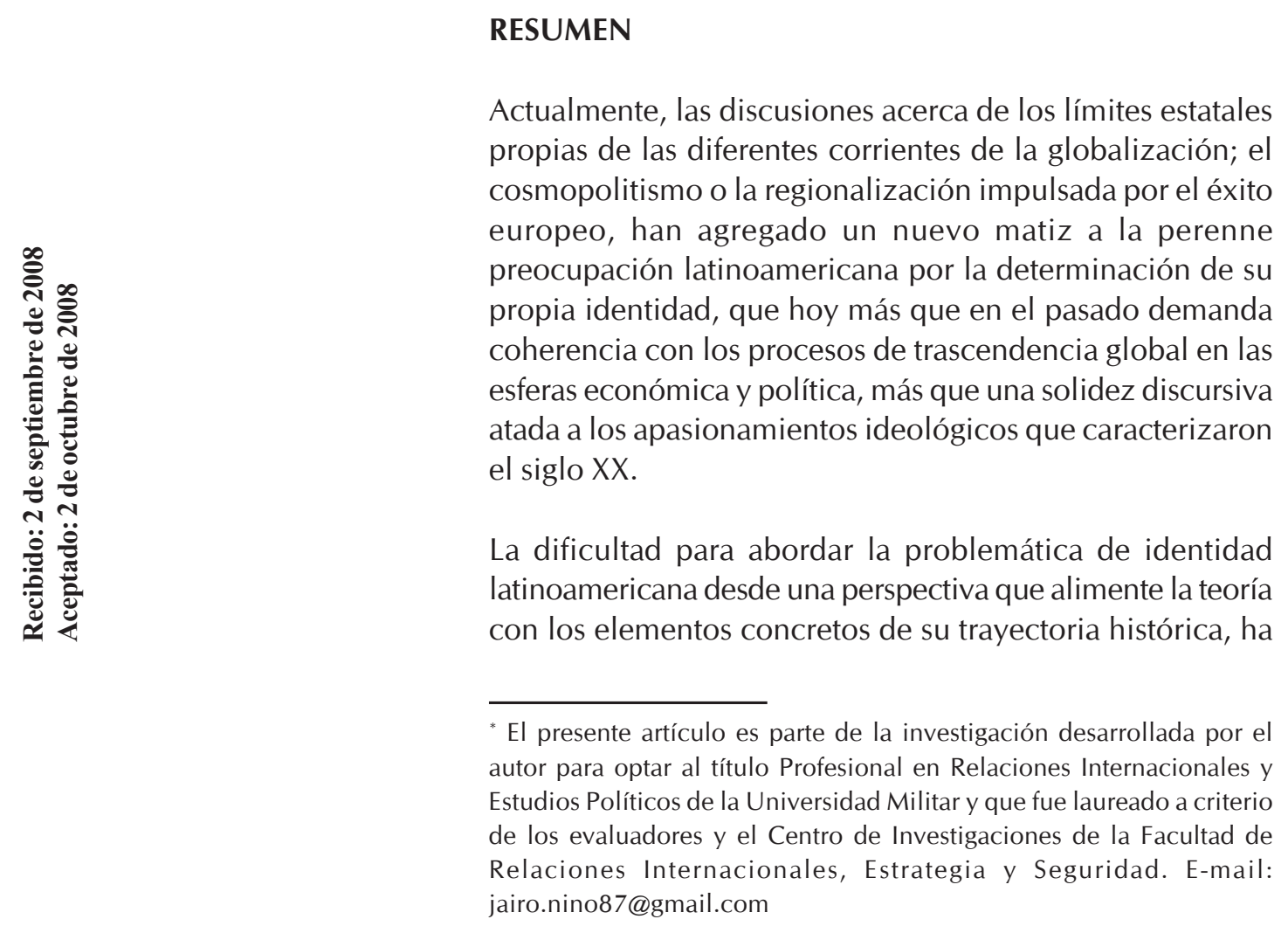


derivado en la proposición de modelos improvisados de asociación regional fundados en la predilección dogmática por una u otra línea de análisis.

Entonces, entender los paradigmas como el prisma a través del cual son percibidos los estímulos del Sistema Internacional y reconocer al mismo tiempo la trayectoria particular que una serie de factores endógenos de carácter regional suponen para Latinoamérica como parte del mundo occidental, que permiten la proposición de modelos teóricos que articulen los elementos étnico - lingüísticos e históricos comunes, con una política exterior comunitaria eficiente.

Palabras Clave: Relaciones Internacionales, Latinoamérica, exterior constitutivo, interior constructivo, constructivismo, modernidad, modernización, civilización, desarrollo, regionalismo, nacionalismo, nacionalismo extendido.

\section{ABSTRACT}

Nowadays, discussion about Estate's limits in the dynamics of globalization; cosmopolitism and regionalization improved by the European success, have added a whole new shade to the everlasting Latin-American worrying about it's own identity's determination which, more than ever before, demands coherence with global economics and politics furthermore than a discursive strength tied to ideology as seen in the twentieth century.

Practical toughness to approach Latin-American identity's dilemma from an all encompassing perspective, regarding in theoretical matters and particular history as well, have come to the application of miscued and improvised models of political association based on dogmatic predilection for one or another line of analysis.

In the understanding of paradigms as the prism trough which International System is conceived and regarding on historical path and the endogenous elements it's defined by as a part of Western civilization, lays the possibility to propose theoretical models for a community based foreign policy, having into account ethnic, linguistic and common history facts.

KEYWORDS International Relations, Latin America, constitutive exterior, constructive interior, constructivism, modernity, modernization, civilization, development, regionalism, nationalism, widespread nationalism. 
Tradicionalmente, la teoría de las Relaciones Internacionales ha sido determinada por aquellos actores que ocupan posiciones privilegiadas en las relaciones de poder tejidas en el Sistema. Por tal razón, las regiones geográficas cuyas posibilidades son limitadas por condiciones materiales adversas, aparecen constantemente como el «objeto paciente» de los esfuerzos teóricos por caracterizar el Sistema Internacional, siendo ésta solo una de las razones por las que se presentan distorsiones respecto a las perspectivas, los objetivos y las aspiraciones de los Estados que las conforman.

El caso latinoamericano es muy Ilamativo al respecto. La región así denominada ha sido considerada parte de lo que se conoció como «tercer mundo», definición que inicialmente connotaba la no pertenencia a la esfera de países industrialmente desarrollados (primer mundo) ni a la de aquellos centralmente planificados (segundo mundo) ${ }^{1}$.

Sin embargo, y pese a que con el fin de la guerra fría el concepto fue reemplazado por otros como el de "países en vías de desarrollo», tal caracterización supuso un papel de segundo orden en el Sistema Internacional y aunque la experiencia histórica demuestra que la región fue escenario de cruentos conflictos directamente relacionados con la dinámica mundial, es limitado el trabajo académico hasta hoy desarrollado que considere la relevancia de los factores endógenos de la sociedad latinoamericana, ya sea como problemática fundamental para los poderes establecidos, o bien como determinante de una postura particular respecto a los procesos globales.

El fin de la guerra fría, además de representar la caída de la tipología bipolar del Sistema Internacional, coincide con el punto de desgaste de un modelo de apropiación y Regulación económica que para el momento arrojaba cifras poco alentadoras para las balanzas comerciales de los países latinoamericanos ${ }^{2}$.

En ese contexto, la pregunta por la identidad latinoamericana irrumpe con gran fuerza en círculos académicos y políticos, esta vez con el matiz de una preocupación por la formulación de políticas para el desarrollo fundadas en la peculiaridad de la región, antes que en la lógica económica internacional que hasta entonces convertía cualquier iniciativa por heterodoxa que fuera, en políticas de ajuste.

\footnotetext{
${ }^{1}$ Gámez, Alba E. «Regionalización y Globalización: Los países en Desarrollo en la política económica internacional de la posguerra fría». Aportes, Revista Facultad de Economía - BUAP. Año VIII, num. 22, pp.: 29.

${ }^{2}$ Córdova, Armando. Crisis económica mundial y futuro de América Latina. En: Pensamiento Crítico: Un diálogo Interregional 2. "Universalismo y Desarrollo. Lander/Sonntag Editores. UNESCO, Rectorado Universidad Central de Venezuela. Ed. Nueva Sociedad. 1991. pp.: $21-40$.
} 
Dicho cuestionamiento por la identidad de la región; centro del estudio cuyas conclusiones son aquí presentadas; continúa sin resolverse, de tal suerte que la dinámica política aún en nuestros días genera incertidumbre y agitación, dándose procesos como lo que se ha popularizado como el "giro a la izquierda» a la vez que los niveles de participación en el comercio internacional de recursos estratégicos como el petróleo aumentan y los mercados mundiales, se muestran sensibles a la difícil conjunción del nivel ideológico con la práctica política de ciertos Estados.

En el escenario de la globalización y el cosmopolitismo actual, existe un alto grado de resistencia y escepticismo frente a la posibilidad de construir una política comunitaria regional, con una carga étnica, lingüística, cultural e histórica particular, que a la vez sea eficiente como modalidad de interlocución en el plano internacional. Creemos, sin embargo, que el dinamismo actual de Latinoamérica y la forma en que participa de los procesos políticos y económicos mundiales, obedecen a una serie de factores que van más allá de la coyuntura internacional y que pueden ser identificados y articulados como base de una política común, construida con un enfoque teórico sólido.

El propósito académico de la investigación desarrollada era, realizar una lectura de las Relaciones Internacionales desde una perspectiva enriquecida por el influjo sistémico Latinoamericano, explorando la naturaleza compleja de este concepto desde su origen, con el objetivo último de proponer un modelo consecuente con las características del Sistema Internacional contemporáneo, tanto como con las condiciones de los Estados Ilamados Latinoamericanos.

En tal sentido, fue necesario realizar un estudio histórico que permitiera identificar la forma en que Latinoamérica llega al periodo de posguerra fría, con el fin de abordar la sección de análisis y conclusión con suficientes elementos de juicio para determinar la novedad, continuidad o intermitencia de diferentes procesos políticos y sociales.

Finalmente y en concordancia con los objetivos planteados, se analizaron las principales variables identificadas a lo largo del estudio ${ }^{3}$ con el fin de ofrecer un panorama general de la región, explorar los efectos prácticos que para la política internacional tiene la categoría de Latinoamericano (con su carga étnica, histórica y lingüística) y la posibilidad (y conveniencia) de hacer de ella un elemento determinante en una estrategia eficaz de participación en el Sistema Internacional contemporáneo.

\footnotetext{
${ }^{3}$ Es decir, los hallazgos en cuanto al concepto de Latinoamérica, su posición diferenciada dentro del mundo occidental, el influjo sistémico de la etnicidad, la raza, el pasado común, así como la metodología más adecuada para incluir estos factores en un modelo de análisis del fenómeno internacional de cara a la toma de decisiones en política exterior.
} 
Puede decirse entonces, que la investigación realizada giró en torno a tres preguntas o cuestiones problemáticas ordenadas de una forma específica, toda vez que la respuesta a la última, estaba sujeta a los hallazgos de las precedentes. Se trata de:

a) ¿Qué es lo Latinoamericano y cuál o cuáles son los criterios para su definición?

b) Considerando el objetivo de ofrecer una propuesta en cuanto a la formulación de un sentido comunitario - regional eficiente en materia de política exterior, ¿ debe seguirse la misma estructura metodológica de los paradigmas clásicos o debe formularse una nueva y bajo qué criterios?

c) La propuesta, considerando nuestro argumento de que en la actualidad la acción política de los países atinoamericanos permite creer que sus factores endógenos tienen una dimensión sustantiva ¿Qué lectura puede hacerse de ella y cuál es el modelo apropiado para convertirla en una herramienta eficiente que materialice los intereses regionales en el diálogo político internacional, es decir, en una política exterior comunitaria para maximizar el influjo sistémico regional?

El presente artículo omitirá la revisión histórica hecha en la investigación original ${ }^{4}$, pero mostrará los hallazgos que ella permitió para la solución de los interrogantes b y c.

\section{EL PROBLEMA METODOLÓGICO DE LA DISCIPLINA EN EL CASO LATINOAMERICANO.}

"El acto de pensamiento por el cual uno cree una cosa es diferente de aquel otro por el cual uno conoce que la cree, y, por lo tanto, muchas veces se encuentra aquel sin éste.»

René Descartes, Discurso del método, parte 3.

Es de uso común, situar el surgimiento de las Relaciones Internacionales en la convulsionada Europa del siglo XVII, con el fin de la Guerra de los Treinta Años. De forma práctica, la paz alcanzada en 1648 en Westfalia significó para las Relaciones Internacionales el fortalecimiento de la figura del Estado como conductor de su actuación internacional sin que para ello deba responder ante instituciones o normas morales superiores, siendo la «Razón de Estado», concepto de origen francés, la justificación máxima y suficiente del comportamiento internacional.

\footnotetext{
${ }^{4}$ Dicha revisión histórica se remitió al análisis de los principales momentos críticos del siglo XX y la forma en que los Estados Latinoamericanos respondieron a los estímulos del Sistema Internacional en momentos como las dos Guerras Mundiales y las crisis económicas de 1929 y 1990. Tampoco se dejó de lado una exploración de la herencia colonial en las instituciones políticas y sociales de la región.
} 
De allí en más, el «Estado - Centrismo» aparecería de manera recurrente en la concepción de las Relaciones Internacionales, tanto en aquellas ideas de origen europeo y relevancia marcada hasta finales del siglo XIX; como en las de origen norteamericano, que irrumpen en la escena internacional en la medida en que la capacidad estadounidense para convertirse en potencia industrial y económica se puso de manifiesto, especialmente con el triunfo en la guerra contra España en 1898.

Tal episodio es particularmente importante por cuanto marca un punto trascendental en la organización del Sistema Internacional y por consiguiente, en los esfuerzos teóricos por caracterizarlo: finalmente los espacios no europeos cobraban relevancia como fuente y escenario de procesos determinantes para el Sistema, dinámica que encontraría su punto culminante con el papel decisivo que jugarían los Estados Unidos en el desenlace de la Primera Guerra Mundial, momento en el cual las Relaciones Internacionales son susceptibles de ser Ilamadas, con más propiedad que en el pasado, una disciplina.

Los acontecimientos posteriores hasta 1945, consolidaron los centros del poder mundial en Estados Unidos y la URSS, nada raro con una Europa en reconstrucción, un Imperio Japonés humillado y un «tercer mundo» irrelevante en la práctica política internacional.

En adelante, y hasta finales de la década de los 80, el carácter bipolar del Sistema lo hizo predecible, y aunque de manera cuestionable, la amenaza de las Armas de Destrucción Masiva (ADM) devino en una política de contención eficiente entre dos potencias con sus respectivas áreas de influencia.

Es este el marco en el que los esfuerzos teóricos por explicar la dinámica de las relaciones en el Sistema Internacional se configuraron, determinando entre otras cosas la forma de organización y la doctrina de los cuerpos responsables de formular y ejercer la política exterior de los Estados. (En el diagrama 1.0 se muestra la dinámica internacional entendida a la luz del modelo clásico).

En ese contexto, se favorecía el establecimiento de ciertas creencias fundamentales para el método de análisis de las Relaciones Internacionales y por consiguiente, de los resultados teóricos que de él emanaban. Cabe resaltar que la orientación de estos esfuerzos era principalmente, la optimización en el proceso de traslación de las necesidades nacionales al sistema rico en recursos para satisfacerlas.

Dicho objetivo, se lograría mediante el establecimiento de vehículos conceptuales, que permitirían justificar un determinado proceder internacional, argumentando su pertinencia con los objetivos nacionales y las condiciones dadas del Sistema, que pueden serle favorables o restrictivas según el momento histórico y los elementos políticos, económicos e incluso ideológicos que privilegia. 
Diagrama 1.0 Modelo Clásico de las Relaciones Internacionales ${ }^{5}$

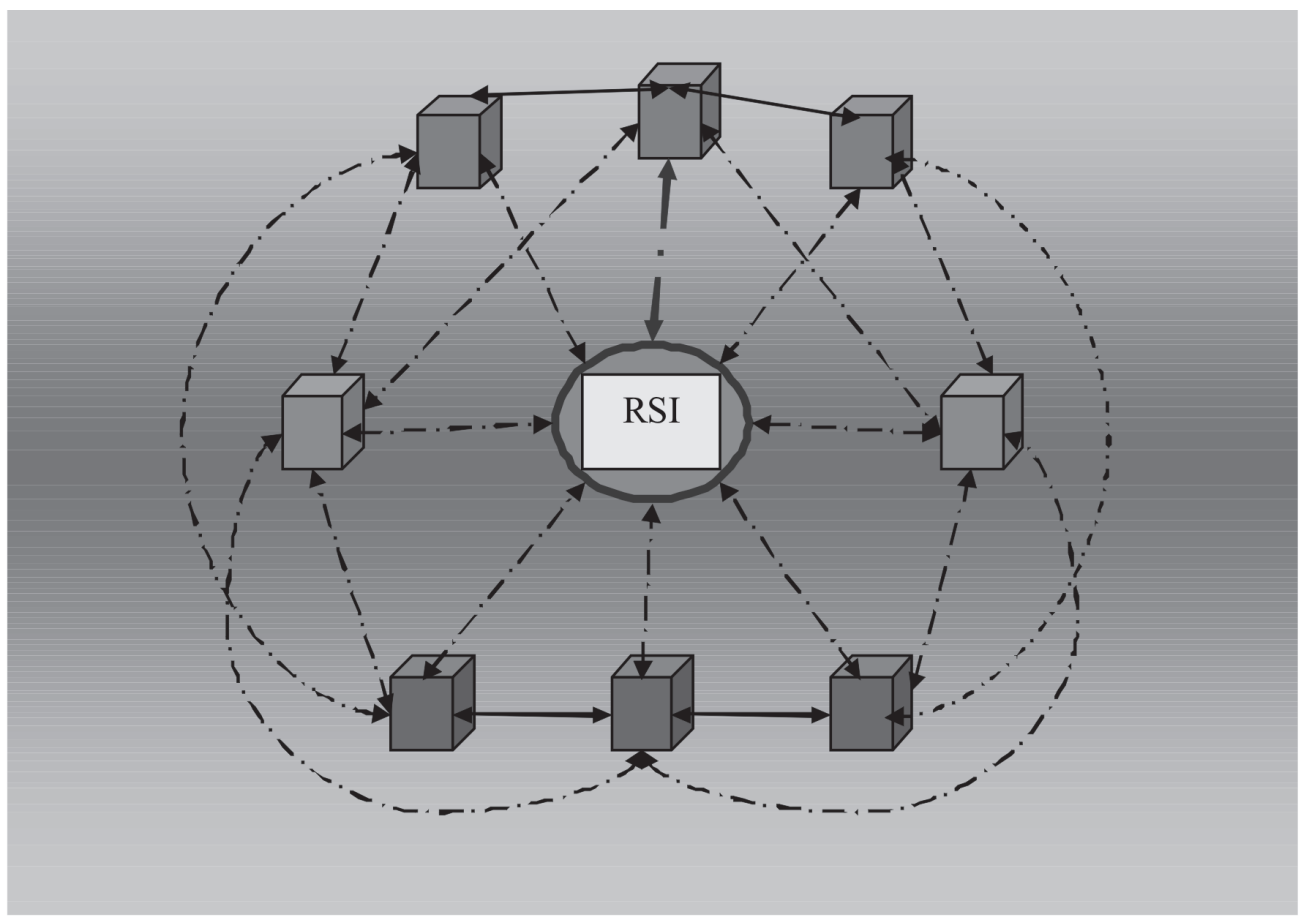

\begin{tabular}{|c|c|c|c|c|c|c|}
\hline & $\pi$ & & & & $--\rightarrow$ & \\
\hline $\begin{array}{l}\text { Estados } \\
\text { alineados }\end{array}$ & $\begin{array}{l}\text { Otros } \\
\text { actores }\end{array}$ & $\begin{array}{l}\text { Estados } \\
\text { hegemónicos } \\
\text { alineados }\end{array}$ & \begin{tabular}{l}
\multicolumn{2}{c}{ Recursos } \\
en el \\
R.S.I.
\end{tabular} & $\begin{array}{l}\text { Condiciones } \\
\text { de acceso a } \\
\text { los recursos }\end{array}$ & $\begin{array}{l}\text { Interaccio } \\
\text { nes no } \\
\text { exclusivas }\end{array}$ & $\begin{array}{l}\text { Relaciones } \\
\text { privilegiadas }\end{array}$ \\
\hline
\end{tabular}

Es así que resulta innegable el sentido histórico que encierra cualquier paradigma, entendido en su sentido contemporáneo como el conjunto de prácticas que definen una disciplina científica durante un periodo específico de tiempo ${ }^{6}$.

\footnotetext{
${ }^{5}$ En el modelo clásico los Estados, en competencia por acceder a los recursos disponibles en el sistema tejen una serie de interacciones no exclusivas. Sin embargo, entre aquellos que se encuentran alineados ya sea por cuestiones ideológicas, políticas o económicas, existen unas relaciones que soportadas en instituciones jurídicas priman sobre las demás y que permiten potenciar los flujos de capital, recursos, información, tecnología y en algunos casos personas entre ellos, con el fin de maximizar el provecho de los recursos obtenidos. Estas interacciones privilegiadas son las denominadas alianzas estratégicas, que benefician al Estado de tal forma que su influjo sistémico aumenta permitiéndole determinar, por encima de sus competidores, las condiciones de acceso a los recursos.
}

${ }^{6}$ KUHN, Thomas. «The Structure of Scientific Revolutions». Chicago and London: University of Chicago Press. 1970. 
Los paradigmas en las Relaciones Internacionales, entendidos a partir de la definición de Kuhn, constituyen el lente a través del cual los estímulos internacionales son percibidos por los académicos como por los encargados de la formulación de la política exterior de los Estados, lo que a su vez determina la realidad del Sistema. Nos enfrentamos entonces al problema metodológico de la disciplina.

Explicar fenómenos internacionales no es el resultado de una concatenación de hechos aislados para su análisis, se trata del estudio (de decisiones políticas) «fundamentado en concepciones y teorías de la realidad mundial en las que son empleados conceptos específicos, por lo que la determinación previa puede partir de otros fundamentos y concepciones surgiendo así el problema epistemológico»?

En el caso del tradicional paradigma realista de las Relaciones Internacionales, la remisión casi obligatoria al trabajo de Morgenthau ${ }^{8}$, refleja una concepción apologética del Estado como actor central que se encuentra en la medida de sus posibilidades materiales, en potencia de ordenar las relaciones interestatales en un sistema anárquico que de cualquier forma, conserva inveteradamente este carácter.

De allí que el Estado, requiera de un cuerpo de toma de decisiones racional (convirtiendo al Estado mismo en un actor racional), que asegure que la conducción de la política exterior correrá siempre en beneficio de los intereses nacionales.

La política exterior latinoamericana, ha sido partícipe de la concepción realista de las Relaciones Internacionales especialmente durante la segunda mitad del siglo XX.

\footnotetext{
${ }^{7}$ ARROYO, Graciela. «Metodología de las RRII. Oxford University Press. 1999

${ }^{8}$ Hans Morgenthau, uno de los mayores representantes del paradigma realista, describió en su obra de 1986, Política entre las naciones: la lucha por el poder y la paz, el realismo político como la conjunción de 6 directrices a saber: a) La política, como la sociedad en general, está gobernada por leyes objetivas arraigadas en la naturaleza humana, que es invariable; por lo tanto es posible desarrollar una teoría racional que refleje estas leyes objetivas. b) El rasgo principal del realismo político es el concepto de interés, definido en términos de poder que infunde un orden racional al objeto de la política, y de ese modo hace posible la comprensión teórica de la política. c) El realismo asume que el interés definido como poder es una categoría objetiva universalmente válida, pero no con una definición fijada de una vez y para siempre. d) El realismo político es consciente del significado moral de la acción política. Es también consciente de la tensión entre el control moral y las exigencias de la acción política eficaz. Por lo tanto, el realismo no es inmoral, sino que su objeto de estudio no es la moral. e) El realismo político se rehúsa a identificar las aspiraciones morales de una nación en particular con las leyes que gobiernan el universo. Es el concepto de interés definido en términos de poder lo que nos salva de los excesos morales y la torpeza política. f) El realista político sostiene la autonomía de la esfera política indagando siempre pos los efectos de la política en el interés de la nación. MORGENTHAU, Hans J. Política entre las naciones: La lucha por el poder y la paz. Buenos Aires: Grupo Editor Latinoamericano, 1986. p. 413.
} 
Si bien, desde los primeros años de las repúblicas independientes, los regímenes personalistas han sido el común denominador en América Latina, lo cierto es que hasta bien entrado el siglo XX aún era plausible algún efecto de la configuración sociocultural de la nación en el carácter del régimen.

Sin embargo desde mediados del siglo XX, cuando la política exterior norteamericana empezó a determinar las formas económicas y políticas en el hemisferio, la tradicional pugna entre las elites locales de los diferentes Estados se vio matizada, con más fuerza que en el pasado, por los factores sistémicos provenientes del exterior.

Ello podría explicarse en gran medida por lo significativo de la decisión de alineación en el panorama de la Guerra Fría, que convenció a los diferentes grupos de interés de la necesidad de asumir el poder para orientar al Estado en una dirección que trajera el bienestar a los ciudadanos ${ }^{9}$.

El punto clave de la discusión aquí planteada, en cuanto a la fortaleza del Realismo, como el marco intelectual que estructurase el pensamiento latinoamericano de cara al conjunto de fenómenos que componen la realidad mundial, está en que el proyecto liberal moderno que encabezaba la gran potencia occidental, mostraba un desprecio marcado por los efectos que tendría el debate acerca de los fines y mecanismos de la vida en común, entre los grupos sociales, inferiores a la categoría estatal, sobre la búsqueda de un orden político y económico eficiente ${ }^{10}$.

De otro lado, la percepción de las Relaciones Internacionales desarrollada desde los enfoques Marxista e Interdependentista, concibe el escenario internacional como un único sistema económico, marcado por el triunfo del capitalismo transnacional.

Estos enfoques enfatizan además en las relaciones de dominación que se tejen en virtud de la capacidad superior de algunos Estados de acaparar los recursos en la mencionada dinámica

\footnotetext{
${ }^{9}$ Este proceso se vio reflejado en los cambios de régimen en el cono sur, cuyo contenido ideológico derivó en un desprecio por los mecanismos de ascenso al poder de tal suerte que las vías de hecho se vieron legitimadas en tal forma que difícilmente puede hacerse alusión a la historia del sur del continente sin hacer reminiscencia de las dictaduras que lo gobernaron hasta la década del 80.

10 Teniendo en cuenta las apreciaciones de Fukuyama sobre los enfoques de la política exterior norteamericana, a saber, neoconservadurismo, (neo)realismo, internacionalismo liberal y nacionalismo «jacksoniano»; es innegable que pese a que todos ellos son descritos como desinteresados por el carácter y la naturaleza de los regímenes políticos de los demás Estados, esta aseveración es fácilmente contestable teniendo en cuenta que las múltiples intervenciones norteamericanas alrededor del mundo, así como el apoyo velado a grupos particulares al interior de diferentes países, culminó en la mayoría de los casos, si no en todos, con el ascenso de un nuevo régimen gobernante. Ver: FUKUYAMA, Francis. "América en la Encrucijada. Democracia, Poder y Herencia Neoconservadora». Ediciones B. S.A., 2007.
} 
económica. La asimetría que ello supone incluye actores de diversa naturaleza (Estados desarrollados, corporaciones transnacionales, multinacionales, bancos, etc.) frente a los cuales aquellos países periféricos se someten en relaciones de desigualdad y explotación.

El enfoque normativo de Marx, identifica a los actores mencionados como agentes de una determinada clase, que en función de sus roles dentro de la dinámica del modo de producción capitalista, ayudan al incremento de la desigualdad.

Es característica común de los países menos desarrollados, acudir a esta perspectiva como fórmula explicativa de su condición de «subdesarrollo». En el caso de Latinoamérica, los presupuestos marxistas acompañaron procesos de nacionalización de factores productivos en Brasil, Perú, Argentina, Bolivia, Chile y Centroamérica durante el siglo XX.

Sin embargo, aunque con el advenimiento de la Industrialización Sustitutiva de Importaciones en los años 70 quedó claro que la utopía autárquica estaba muy lejos de materializarse, los planteamientos marxistas fueron desvirtuados mucho antes. Cuando los movimientos revolucionarios latinoamericanos obtuvieron algún éxito, su incapacidad para generar una estructura gubernamental igualitaria quedó de manifiesto ${ }^{11}$, dejando claro que las relaciones entre sujetos y actores (estatales y no estatales) tienen muchos más determinantes que la esfera económica.

Por su parte, la interdependencia de Keohane y Nye, antecedente del paradigma de la «Sociedad Mundial», reconoce igualmente la superioridad de la esfera económica sobre la política en las relaciones internacionales. Sin embargo, este enfoque se aparta del marxismo ya que permite concebir asociaciones de individuos por fuera de la categorización de clase.

Probablemente lo más característico de este enfoque es el supuesto desvanecimiento de las fronteras entre lo estatal y lo internacional ${ }^{12}$, considerando que existen actores y amenazas que se mueven indiferentemente en ambos escenarios.

\footnotetext{
${ }^{11}$ «La historia de Latinoamérica está Ilena de sustitutivos de la izquierda revolucionaria social auténticamente popular que raramente ha tenido fuerza suficiente para determinar la configuración de la historia de sus países. La historia de la izquierda latinoamericana es, salvo raras excepciones, [...] la de tener que escoger entre una pureza sectaria e ineficaz y hacer el mejor de varios tipos de mal negocio, de escoger entre populistas militares o civiles, entre burguesías nacionales o de cualquier otro tipo. Es también, a menudo, la historia de la izquierda que lamenta no haber sabido acomodarse a esos gobiernos y a esos movimientos antes de que fueran sustituidos por algo peor». HOBSBAWM, Eric. Años interesantes, Una vida en el siglo XXI. Editorial Crítica. Barcelona, 2003. pp. 345.

${ }^{12}$ Los tres supuestos fundamentales del planteamiento de Keohane y Nye son la existencia de múltiples canales intergubernamentales y transnacionales de interacción social; la ausencia de jerarquía entre los problemas de la agenda internacional sumada al desvanecimiento de los límites entre lo interno y lo externo y la primacía de la cooperación sobre la fuerza militar en los vínculos entre actores. KEOHANE, Robert y NYE, Joseph. Poder e interdependencia: la política mundial en transición. Buenos Aires: Grupo Editor Latinoamericano. 1988. pp. 305.
} 
El supuesto interdependentista que mejor asiento ha tenido en las relaciones internacionales de Latinoamérica, es aquel que privilegia la cooperación sobre la fuerza militar en las interacciones entre los diferentes actores. Esta característica, dicho sea de paso, diferencia el «tercer mundo» Latinoamericano del localizado en Europa Oriental, Asia y África, teniendo en cuenta que los nacionalismos étnicos y confesionales de esas latitudes los hacen más proclives al uso de la fuerza militar.

De cualquier forma, el escenario Latinoamericano ha evidenciado una dificultad importante para superar las fronteras nacionales como plataforma de interacción en el sistema internacional. Entre otras cosas, por cuanto las sociedades insatisfechas tienden a reforzar las jerarquías para procurarse un esquema de adjudicación de responsabilidades, lo que lógicamente deriva, en la predilección por estructuras locales de acceso a la tecnología y el capital por encima de la ambigüedad de lo transnacional.

Además, la permanencia de regímenes políticos con base en poderes ejecutivos fuertes, ha limitado históricamente la formulación de nuevas estructuras de administración del poder. Levi Strauss, en su «Derecho Natural e Historia» de 1953, concibe la importancia de los regímenes políticos, en tanto que considera necesaria su mutación para modificar ciertos comportamientos sociales, lo que sin embargo, era una meta muy difícil de conseguir ${ }^{13}$.

El personalismo de los regímenes políticos latinoamericanos, favoreció el establecimiento de posturas de corte realista, que limitaron la capacidad de sus sociedades para encontrar su espacio de participación, por lo que las discusiones políticas al interior del Estado se centran en la preocupación por la movilidad social en el esquema de poder preestablecido, antes que en concebir un escenario no estatal de acción política.

\section{UNA CONSIDERACIÓN FINAL RESPECTO AL MÉTODO.}

Habiendo resaltado algunos de los problemas en la aplicación de los enfoques tradicionales de las Relaciones Internacionales al caso latinoamericano, restan unos comentarios finales que demostrarán la pertinencia del enfoque desarrollado en el presente estudio.

Como se ha visto, entendemos que la variable histórica debe tenerse en cuenta en tanto espacio de reproducción y desarrollo del carácter de las sociedades, más que como una simple magnitud de la presencia temporal de ellas en la realidad.

${ }^{13}$ FUKUYAMA, Francis. "América en la Encrucijada. Democracia, Poder y Herencia Neoconservadora». Ediciones B. S.A., 2007. pp. 43 
Consideramos, que el conocido argumento de que el desprecio del análisis histórico en la adopción y ejecución de estrategias políticas y económicas es un agente generador de distorsiones importantes, es algo que esas disciplinas comparten con las Relaciones Internacionales ${ }^{14}$.

Sin embargo, es también equivocado sugerir, que el simple vínculo histórico y los matices que haya tomado en relación con elementos como la cultura y la raza, son suficientes para proponer un marco de acción internacional sobre una base comunitaria, que pueda ser efectivo como estrategia de política exterior mancomunada.

Por tal razón, con el afán de no incurrir en el «desorden macro sociológico» ${ }^{15}$ propuesto por Bradie, en la búsqueda de un criterio identitario para una política exterior comunitaria, asumimos la posición del politólogo francés, cuando señala respecto al análisis internacional que [Los análisis] «deben hacerse a manera de trayectorias, ya que las sociedades no dependen de la evolución o progreso generales sino de su historia $[\ldots]{ }^{16}$.

En virtud de ello, para descifrar el criterio de identidad latinoamericano, la metodología adoptada incluyó un análisis de doble vía así:

- Análisis Histórico - Concreto: A partir del cual puede hablarse de Latinoamérica como todos aquellos Estados occidentales que comparten un origen colonial en las potencias de la cuenca del mediterráneo, y que han evolucionado en sus formas políticas y sociales a partir de dicha herencia.

- Análisis Lógico Constructivo: Según el cual, las similitudes en cuanto al funcionamiento y organización de Occidente son tales, que no puede separarse de forma práctica a los Estados descritos en el análisis histórico concreto del resto de Occidente, por cuanto las diferencias en materia económica y de desarrollo industrial permiten otras categorías de análisis. (Tercer mundo, países en vías de desarrollo, etc.).

\footnotetext{
${ }^{14}$ Considerando que las RRII pretenden explicar la naturaleza y la dinámica de diferentes fenómenos internacionales que son tocados de manera más que tangencial por dinámicas económicas y políticas.

${ }^{15}$ Aquel desatino que se produce cuando en busca de lo singular, se globaliza. Este problema es evidente tanto en el paradigma tradicional de la sociedad mundial como en los planteamientos posmodernos que rayan en el relativismo cultural

${ }^{16}$ BERTRAND, Badie. Análisis comparativo y sociología histórica, Revue Internationale des Sciences Sociales, UNESCO, número 133. Agosto de 1992. París. Pp. 163 - 372.
} 


\section{UNA LECTURA ALTERNATIVA.}

\section{Recapitulación.}

Hasta ahora, de los tres problemas fundamentales planteados para la formulación de una base teórica que estructure un sentido comunitario eficiente para Latinoamérica, es decir, que maximice el influjo sistémico regional de cara a los procesos determinantes para el sistema, se ha ofrecido una respuesta a dos de ellos:

En primer lugar, respecto a la cuestión problemática del criterio de definición de «lo Latinoamericano", se ha anotado que con base en la articulación del análisis Histórico - Concreto, desarrollado en la fase de observación y el Lógico - Constructivo, intrínseco al marco teórico de todo el estudio, puede definirse que aquellos Estados Occidentales que comparten un origen colonial en las potencias de la cuenca del mediterráneo y que han evolucionado en sus formas políticas y sociales a partir de dicha herencia, pueden desarrollar una identidad latinoamericana fundada en una significación social imaginaria ${ }^{17}$, derivada del curso común ${ }^{18}$ que dichos Estados siguieron en el desarrollo de la modernidad, a partir del siglo XVIII.

En segundo lugar, en cuanto a los cuestionamientos alrededor del problema metodológico de las Relaciones Internacionales, acerca de la pertinencia de los modelos teóricos y paradigmáticos de la disciplina como eje conceptual para la articulación de dicha política de comunidad para la región, se ha anotado que: como lo señala Ansaldi, las sociedades latinoamericanas pueden estudiarse con el mismo utillaje teórico empleado para los líderes del proyecto civilizacional occidental ${ }^{19}$.

\footnotetext{
${ }_{17}$ Castoriadis señala que todas las sociedades necesitan crear su propio mundo de «significaciones sociales imaginarias» para mantenerse unida como sociedad. Dichas significaciones son imaginarias en el sentido de que no corresponden a elementos racionales o reales, y sociales en la medida en que solo existen estando instituidas y siendo objeto de participación de un ente colectivo, impersonal y anónimo. De acuerdo con este planteamiento, mediante el refuerzo de algunos de los elementos que describen la trayectoria común de la que habla Bradie en América Latina, puede hablarse de la conformación de una significación social imaginaria de comunidad Latinoamericana. CASTORIADIS, Cornelius. "Las Raíces Psíquicas y Sociales del odio». En: SILVEIRA, Héctor. "La vida en común en las sociedades multiculturales». Recopilado en : SILVEIRA, Hector (editor). Identidades Comunitarias y Democracia. Editorial Trotta. Madrid. 2000.

${ }^{18}$ Encuanto a este c urso común puede hablarse de la adopción de la nacionalidad vinculada al Estado territorial como forma de identidad primaria o la adopción de las teorías racionalistas/materialistas como marco normativo y explicativo de las relaciones sociales e internacionales.

${ }^{19}$ Originalmente, Ansaldi habla de las [sociedades] del centro del sistema capitalista mundial. ANSALDI, Waldo. La Temporalidad Mixta de América Latina. Una Expresión de Multiculturalismo. En: SILVEIRA, Héctor (editor). Identidades Comunitarias y Democracia. Editorial Trotta. Madrid. 2000. p. 168.
} 
Por consiguiente, reconociendo que los elementos del análisis Lógico Constructivo, señalan que los parámetros de organización y funcionamiento de Latinoamérica no se separan en lo fundamental de los del resto de la civilización occidental, es posible utilizar como se ha hecho hasta ahora por académicos y políticos, las mismas bases y conceptos teóricos que han orientado el estudio y la práctica de las Relaciones Internacionales en Europa y Norteamérica.

Con esto claro, frente al último interrogante propuesto, que es al mismo tiempo la respuesta sugerida a la búsqueda por esa base conceptual sobre la cual estructurar una política de comunidad latinoamericana, se presenta a continuación, una propuesta fundada en los hallazgos descritos.

Básicamente, dichos hallazgos se articularán de tal forma que la teoría (construida desde una perspectiva lógica instrumental que engloba a todo Occidente), se vería enriquecida por los elementos "civilizacionales» y valores compartidos alternativos de Latinoamérica (construidos con el paso del tiempo y el devenir histórico que separa a los estados definidos como latinoamericanos de acuerdo al criterio establecido en el capítulo anteriormente, del resto de Occidente).

\section{Mitos sobre nación y universalismo.}

Para empezar, haremos algunas consideraciones respecto a los supuestos que en el pensamiento político contemporáneo en América Latina, son concebidos como básicos y constantes, es decir, todas aquellas nociones que se entienden como variables independientes en el sistema y que por consiguiente, afectan de manera determinante el comportamiento de los actores.

La Ilustración dejó como legado para el mundo, dos de los principales presupuestos para la perspectiva occidental de la vida en comunidad.

Por una parte, la nación política como agente activo del poder del Estado en su doble función de depositario (es el pueblo, vinculado por la nación étnico - lingüística quien cede el poder al Estado que lo administra) y de beneficiario del mismo (El poder conferido al Estado debe garantizar la seguridad de los asociados a él ${ }^{20}$. De otro lado, se encuentra la construcción ideológica del universalismo teóricamente alcanzable en virtud de la dinámica liberal y cuyas contradicciones lo desmembraron, a finales de la década del 80, en el comienzo de una disputa aún inconclusa entre el cosmopolitismo y el globalismo neoliberal.

Vamos con la nación. Ante todo, es importante hacer claridad sobre el hecho de que la nación política, instituida en el siglo XVIII, surge de la conciencia misma de que la circunscripción a un

\footnotetext{
${ }^{20}$ Aquí se hace plausible el carácter contractual y consensual de la nación sobre el cual se discutirá más adelante.
} 
gobierno Estatal no excluía la afiliación o lealtad a otra colectividad de carácter familiar, tribal, religioso, etc.

Por tal razón, frente a una falla operativa del Estado en a la satisfacción de las necesidades de alguno de los pequeños colectivos aunados en su seno, la posibilidad de terminar la relación contractual y por consiguiente del desmembramiento del Estado, debía ser limitada mediante un elemento de cohesión tal que escapara a miramientos formales y echara raíces emocionales en el imaginario de todos los asociados.

Tal elemento de cohesión, buscaría polarizar las relaciones del grupo de tal forma que todos los miembros del grupo «nosotros» traten a todos los miembros del grupo «ellos» como enemigos peligrosos en potencia, y sientan por tanto una identificación total con «nuestro» grupo como su única protección ${ }^{21}$. En tal sentido, el Estado - Nación prevalece a las tempestades políticas que puedan darse a su interior como única estrategia de protección frente al exterior hostil.

Ese es el origen de la identidad por excelencia del individuo moderno, la que emana del Estado territorial, convertido en un proceso inicialmente consensual y contractual, en Estado - Nacional, siendo hoy ambos términos (Estado y Nación) usados casi de manera indiferente para designar a la entidad sociopolítica del Estado.

Lo que se quiere aquí resaltar es que el vinculo Estado - Nación, es resultado de una necesidad operativa de definir al "pueblo» de un Estado como el habitante de un territorio preexistente ${ }^{22}, y$ no una relación natural y/o predeterminada.

Al respecto Balibar y Wallerstein comentan:

Por el hecho de que hoy sean tres Estados, ¿significa que hay tres naciones? ¿Existen hoy una nación Belga, una Holandesa, una Luxemburguesa? La mayoría de los observadores así parece creerlo. Y si existiesen. ¿No es quizá porque antes surgió un Estado Holandés, uno Belga y uno Luxemburgués? Una mirada sistemática a la historia del mundo revelará, creo, que en casi todos los casos la noción de Estado ha precedido a la de nación y no al revés, a pesar de lo difundido del mito contrario. ${ }^{23}$

En este punto, puede decirse entonces que si bien es cierto el difundido argumento con el cual se pretende explicar las convulsionadas relaciones sociales de los países latinoamericanos, así

\footnotetext{
${ }^{21}$ HOBSBAWM, Eric. Identidad. Recopilado en : GORSKI, Hector (editor). Identidades Comunitarias y Democracia. Editorial Trotta. Madrid. 2000.

${ }^{22}$ Ibíd.

${ }^{23}$ BALIBAR, Etiene y WALLERSTEIN, Immanuel. Raza, Nación y Clase. Instituto de Estudios Políticos para América Latina y África. Madrid, 1991. p. 91.
} 
como algunas de sus deficiencias institucionales de que la constitución del Estado precedió a la construcción nacional, ello no es un hecho tan aislado como se pretende mostrar. Además, en una mirada más amplia, puede decirse incluso que los sentimientos entendidos como nacionales (en su significación primaria étnico lingüística) existían ya en escenarios aún más abiertos.

En cuanto al universalismo, que en el siglo XX se instituye como necesidad compartida de los regímenes antagónicos capitalistas y comunistas, debe traerse a colación aquí la contradicción señalada por autores desde Marx, pasando por Weber y Durkheim, hasta Wallerstein y Hobsbawm.

La filosofía de la historia de Hegel supone un «dispositivo teórico de inclusión y de exclusión de los continentes y los pueblos que participan en la sucesión progresiva del tiempo histórico Universal». De tal suerte, que como lo señala Hegel de manera expresa, continentes enteros como el africano no poseen una historia propia, dado que no se trata de un continente histórico ya que todos los movimientos y desarrollos sucedidos en su parte septentrional corresponden al mundo asiático y europeo.

Esta afirmación de Hegel, en una obra en la que además no hace mejores comentarios sobre «los Latinoamericanos», deja entrever la necesidad universalista de determinar límites que niegan su propio carácter.

La relación entre el universalismo y la nación en la modernidad, se perfeccionó en función de un entendimiento del fenómeno social como un escenario de sumisión a algo común,considerado más alto. Entonces, la noción de lo universal no solo admite la exclusión latente en la superioridad de un Estado que materialice valores superiores y por consiguiente necesarios para todos, sino que le es necesaria dicha diferencia. De otra forma, no existirían esas imágenes de comunidad que proporciona en el modelo para la formación de la identidad colectiva universal.

En esta relación de superioridad, en la lucha de las dos grandes ideologías del siglo XX los claros perdedores son identificables en las áreas de influencia de las superpotencias. El régimen comunista como representante de un universalismo proletario fue incapaz de consolidar una nación política de la suma de todas las naciones étnicas que agrupaba en la entidad de la URSS.

De manera muy apropiada lacono señala que «la quiebra de los regímenes comunistas, testimonia quizá el último intento por imponer un universalismo heredado de la llustración, a varias naciones unificadas por un Estado. Y esta quiebra, ha consistido también en la incapacidad de proponer y de crear identidades colectivas y valores compartidos alternativos a los propuestos y engendrados en la edad moderna, tales como la raza, la nación, el pueblo, y a su naturalización». ${ }^{24}$

${ }^{24}$ IACONO, Alfonso. Raza, Nación, Pueblo: Caras Ocultas del Universalismo. En: SILVEIRA, Hector (editor). Identidades Comunitarias y Democracia. Editorial Trotta. Madrid. 2000. P. 108. 
Es hora de acercarnos al caso latinoamericano en esta dinámica. Si bien el estrepitoso colapso de la URSS y el estallido de los nacionalismos con derramamiento de sangre en Europa Oriental, hizo visible la carencia señalada por lacono respecto a la construcción de valores compartidos, lo cierto es que dicha falencia se dio igualmente en América latina, donde sin embargo los procesos históricos que determinaron su configuración desde el siglo $X \mathrm{~V}^{25}$, la hacían para finales de los 80 un escenario menos conflictivo al menos en el ámbito interestatal ${ }^{26}$.

Lo que con el declive de la guerra fría fue en Europa Oriental una lucha por la autodeterminación fundada en viejas reivindicaciones étnicas, raciales y religiosas; en América Latina, corresponde a la continuación de un proceso que comenzó hace casi dos siglos por la constitución exitosa del propio estado nacional moderno.

Podemos afirmar, que el fin de la guerra fría y las dos décadas subsiguientes no han traído para Latinoamérica un cambio radical en la dinámica política pese a lo difundido del supuesto quiebre materializado en el Ilamado "giro a la izquierda" y a los efectos transformadores del 11 de septiembre de 2.001, como falso punto de inflexión en el Sistema Internacional contemporáneo.

Si se toma el ejemplo de los Estados económicamente más sólidos en la región, más allá del discurso político y una variación - no muy sustancial - en la organización de la producción en Venezuela, Brasil y Chile, lo que ha alentado el distanciamiento en materia de política económica de Latinoamérica frente a Estados Unidos después de 1.990, ha sido la búsqueda de concretar para sí los beneficios de los valores universales encarnados en la democracia liberal norteamericana ${ }^{27}$.

Nación y Universalismo, son aspiraciones occidentales buscadas desde el vehículo del Estado territorial a las que Latinoamérica no escapa. Entonces, desde la perspectiva propuesta, el debate

${ }^{25}$ Entre los procesos a los que se hace referencia, están los descritos en el capítulo 1, como son la herencia colonial, la homogeneidad religiosa, el curso más o menos adecuado que se le dio a la problemática racial y el carácter menos restrictivo del bloque capitalista en un sentido organizacional, comparado con el férreo control soviético para mantener unidos a los diferentes pueblos. La importancia de la dinámica organizacional en, primero, la restricción y, después, el estallido de los nacionalismos puede verse en el ejemplo Yugoslavo, cuando la figura carismática desaparece, la organización se diluye y la guerra sobreviene.

${ }^{26}$ Considerando claro que los conflictos latinoamericanos, a diferencia de Europa oriental y África obedecen a reacciones de tipo más económico y social que étnico, religioso o cultural.

${ }^{27}$ En este sentido, Wallerstein afirma que incluso los cambios y presiones en el plano cultural motivados por la puesta en marcha de los mecanismos de expansión económica [del sistema de economía mundo capitalista] y que obedecen a lo que se define como occidentalización o modernización, hallaban su legitimación en «el deseo de repartirse la fe en la ideología del universalismo juntamente con sus frutos». WALLERSTEIN, Immanuel. EI Capitalismo Histórico, Editorial Siglo XXI. México, 1988. P. 66. 
por la identidad latinoamericana no es tanto una lucha por la diferenciación respecto al modelo democrático - liberal, sino la búsqueda de la consolidación del mismo en función de unos valores propios (que son los que aún están por definir) y en procura de la conservación de los valores tradicionales (aquellos enmarcados en el plano étnico, cultural e histórico).

\section{La «invención de la tradición» latinoamericana en el siglo XXI.}

Ranger y Hobsbawm, en su obra conjunta de 1991 «La Invención de la Tradición» ${ }^{28}$, explican la forma en que la separación entre los valores antiguos y aquellos construidos por acción - reacción frente al sistema económico mundial, es salvada por el proceso que da el título a su obra.

El concepto de tradición inventada, es evidente en los procesos políticos de mayor envergadura en Latinoamérica desde finales de los 80 y que cobraron especial fuerza desde mediados de los 90; cuando con la región sumergida en la mayor crisis macroeconómica de que se tenga cuenta y con la experiencia poco satisfactoria de la Industrialización Sustitutiva de Importaciones $(\mathrm{ISI})^{29}$, los cuestionamientos respecto al cómo ${ }^{30}$ acceder al bienestar, ganaron mayor protagonismo en la práctica política y de las relaciones internacionales de Latinoamérica.

Es así, que el panamericanismo que fuera la motivación para la institucionalización de asociaciones interestatales durante la segunda mitad del siglo XX, es reemplazado por una serie de iniciativas regionales como el MERCOSUR (1994) y el ALBA (2004), al tiempo que la asociación de naciones andinas deja de ser «pacto» para instituirse en «Comunidad» Andina en 1996.

El Bolivarianismo, que se ha pretendido mostrar como germen y base axiológica de una política comunitaria latinoamericana, es decir, como la propuesta vigente para la cuestión fundamental de este estudio (y cuya inconveniencia será discutida en el apartado siguiente), es el ejemplo más claro de la forma en que el proceso de invención de la tradición se presenta en las iniciativas regionales de integración.

La capacidad económica ascendente de Venezuela, convirtió a su esfera ejecutiva en vocero teóricamente legítimo, de las demandas de la región frente al sistema económico mundial y al

${ }^{28}$ HOBSBAWM, Eric y RANGER, Terence. L'invenzione della Tradizzione, Torino. 1991

${ }^{29} \mathrm{Si}$ bien la Industrialización Sustitutiva de Importaciones fue extendida a toda la región, su naturaleza misma la convertía en un proceso similar entre Estados no interactuantes, por lo que su ejecución por fuera de la supervisión de la CEPAL se hallaba sujeta al plano netamente nacional.

${ }^{30}$ Como se ha señalado a lo largo del estudio, el motor del distanciamiento en materia de política económica entre Latinoamérica y Estados Unidos es el cuestionamiento frente a los mecanismos para acceder al bienestar, pues el concepto de «bienestar» es el mismo heredado de la ética utilitarista para ambas partes del continente. 
Bolivarianismo ${ }^{31}$, en el vínculo regional que por fin y tras dos siglos de vida republicana, tendría un carácter netamente endógeno.

Sin embargo, el bolivarianismo - proyecto, que busca convertirse en una identidad colectiva, acude al bolivarianismo - concepto, para proveerse de una legitimidad histórica ya que como señala lacono en relación con el planteamiento de Hobsbawm y Ranger, «el paso a la nueva forma de identidad colectiva depende de la relación que esta instituye con el pasado ${ }^{32}$ ».

En los últimos 10 años, hemos acudido a la invención de la tradición latinoamericana en la búsqueda de un vehículo común para acceder a los recursos del Sistema, reivindicando una diferencia dentro de la civilización occidental, por cuenta de imaginarios aglutinantes que se frustran ante elementos de mayor alcance como la lengua y que sin embargo, no alcanzan para servir de plataforma a una identidad colectiva políticamente practicable.

\section{Una visión constructivista de las relaciones internacionales y la política exterior.}

Con los elementos obtenidos a partir de la aplicación teórica sobre los hallazgos emanados de la revisión histórica de los Estados latinoamericanos y sus respuestas ante estímulos sistémicos comunes, podemos ahora formular algunas propuestas a la cuestión fundamental planteada.

Para empezar, debe reconocerse una serie de continuidades históricas que permiten concluir, que si bien la pregunta por la identidad latinoamericana persiste en el tiempo y está lejos de ser resuelta en su totalidad, su respuesta pertenece a un marco claramente establecido dentro el proyecto civilizacional occidental y va más allá de las diferencias establecidas desde la perspectiva racial y étnica.

Al mismo tiempo, dichas continuidades ofrecen un aporte en cuanto a la cuestión metodológica para quienes abordan este campo de estudio considerando que las dinámicas sociales, políticas y económicas descritas, (entre ellas las respuestas a los estímulos sistémicos) en los Estados latinoamericanos, son semejantes a las de Estados Unidos y Europa ya que comparten un origen histórico común y un ideal de bienestar no muy distante. Dichas continuidades son:

\footnotetext{
${ }^{31}$ Que es entendido como la noción instrumental de la herencia colonial, fundada en una concepción imaginaria de unidad inspirada, en una pequeña medida, en ideas planteadas por el General Simón Bolívar.

32 IACONO, Alfonso. Raza, Nación, Pueblo: Caras Ocultas del Universalismo. En: SILVEIRA, Héctor (editor). Identidades Comunitarias y Democracia. Editorial Trotta. Madrid. 2000. P. 103.
} 
1) La Matriz Estadocéntrica ${ }^{33}$ : Desde el siglo XVIII cuando las ideas revolucionarias de emancipación empezaron a encontrar asiento en el continente, la idea del Estado Nacional moderno ha permanecido en el imaginario de los colectivos sociales latinoamericanos; siendo la idea de bienestar una suerte de realizaciones en materia económica y política al interior del mismo (que es una especie de síntesis de la sociedad) y que se verían reflejadas en el mejoramiento de la calidad de vida de los asociados, reunidos por el vínculo de la nación étnico - lingüística y que ejercen su poder cediéndolo como «pueblo» o nación política, al bien común perseguido y ejecutado por el Estado.

2) Procesos Traslapados: América Latina, como se ha dicho reiteradamente, es un proyecto occidental moderno. Por tanto, ha perseguido con ahínco los objetivos históricos europeos y norteamericanos y ha sido objeto paciente de su instrumentalización ${ }^{34}$. Civilidad, Modernidad y Desarrollo ${ }^{35}$ constituyen los nortes históricos de Latinoamérica siendo difícil distinguir el paso de uno a otro; de tal suerte que mientras las tareas de la modernidad se debaten en las academias, los actores políticos y cuerpos oficiales planean y ejecutan estrategias para alcanzar el Desarrollo. Esta problemática entre Civilización, Modernización y Desarrollo ha estado presente desde la época colonial jalonada por dos motivos claros: la eficiencia económica y la seguridad política ${ }^{36}$. Estas, sin embargo, han estado referidas a fenómenos técnicos diversos según el momento histórico ya sea la evangelización y alfabetización; el establecimiento de la democracia liberal o la inserción sostenible en la economía mundial, respectivamente.

\footnotetext{
${ }^{33}$ La Matriz Estadocéntrica es definida por Jorge Iván Cuervo Restrepo como aquella herencia de los modelos teóricos europeos que dan por sentado que el Estado es una especie de representación de la sociedad. Comenta además que en Latinoamérica esta se resuelve a favor del Estado, con los poderes ejecutivos en cabeza y en detrimento de los parlamentos y la sociedad civil. Además cita a Marcelo Cavarrozzi señalando que lo que caracteriza la Matriz Estadocéntrica como signo distintivo de los regímenes en América Latina es que las estructuras sociales, políticas y económicas evolucionaron a partir de la acción del Estado. CUERVO, Jorge Iván. El Ajuste Estructural, la Política y las Instituciones. El Caso Chileno y Conjeturas sobre Argentina. Universidad Externado de Colombia. Pp. 271 - 306. Ver también: CAVARROZZI, Marcelo. Partidos Políticos, Desestatización y Reforma Estructural: ¿El Retorno de la Política en América Latina? En: CARRILLO, Fernando (ed.) Democracia en Déficit. Gobernabilidad y Desarrollo en América Latina y el Caribe, Washington, BID, 2001.

${ }^{34}$ Como señala el sociólogo peruano Aníbal Quijano, «América Latina es tanto víctima tardía y casi pasiva de la modernización, cuanto partícipe activa en el proceso productor de la modernidad, cuyos comienzos pueden situarse en el violento encuentro que América y Europa experimentan a finales del siglo XV»

${ }^{35}$ Así como el concepto de «civilidad» del siglo XVI en Europa se convirtió en «civilización» al sumarse la concepción instrumental del mismo, es decir, cuando se concibe la tarea de «civilizar» al otro, la modernidad se instrumentalizó en el paso del mercantilismo al capitalismo industrial y el establecimiento de instituciones formales que regularan apropiadamente las relaciones en el Estado. En la actualidad, el concepto de desarrollo es un neologismo de características similares cuya trascendencia es tal, que incluso es fuente de prejuicios raciales y culturales.

${ }^{36}$ WALLERSTEIN, Immanuel. El Capitalismo Histórico. Ed. Siglo XXI, México. 1988. pp. 66 - 69.
} 
Otro elemento, que permanece constante en las esferas teórica y práctica de la política y las Relaciones Internacionales en occidente, incluida Latinoamérica, es la preocupación por la naturaleza, el concepto y las implicaciones del Poder.

Sin embargo, la preocupación por el poder no se incluyó en las continuidades enumeradas por cuanto es un elemento considerablemente más subjetivo, ya sea por la ambigüedad del concepto mismo ${ }^{37}$ o porque para diferentes esferas occidentales la percepción del poder varía según como es evaluada la dinámica del Sistema Internacional.

Esta es una de las diferencias evidentes entre Latinoamérica y los líderes del proyecto occidental; mientras que Estados Unidos; Europa y Rusia conciben sus interrelaciones en el sistema como mecanismos de ascenso en una dinámica de poder; Latinoamérica concibe las suyas como instrumentos de inserción en una dinámica de cooperación para alcanzar el Desarrollo. De hecho, cuando los líderes de Occidente acuden a mecanismos de alta cooperación ello obedece a fallas en sus sistemas de alianzas o a una falla operativa para lidiar con alguna amenaza que excede su capacidad.

En el diagrama 2.0, se ejemplifica la relación de los elementos determinantes en la concepción de las Relaciones Internacionales para el Occidente Desarrollado y para Latinoamérica. Se observa que al ser el Desarrollo una variable resuelta, el Occidente desarrollado privilegia en su percepción del Sistema Internacional la idea de maximización del poder sustantivo, que puede llegar a ser hegemónico en la medida en que sus interacciones se den en una dinámica de Alianza Estratégica en contraposición a la cooperación entre iguales.

Por su parte, Latinoamérica más que por la búsqueda de hegemonía, pugna por la maximización de sus posibilidades de inserción autodeterminada en el Sistema en una dinámica que privilegia la cooperación, entendiendo que la dinámica de Alianzas estratégicas, por su carácter supone la alineación con una potencia global que necesariamente condiciona la acción autónoma.

De esto se entiende, que la actualidad del Sistema Internacional supone unas particularidades claras en la lógica de ejecución de la política exterior y las relaciones internacionales para Latinoamérica, dadas en función de unas condiciones materiales y unos objetivos comunes. Lo que sigue ahora, es sugerir una fórmula para articular esas similitudes materiales con una

\footnotetext{
${ }^{37}$ El Poder, como cualquier otra construcción lingüística está sujeta a cambios sustanciales en diferentes momentos históricos y se ve afectada por la evolución de las técnicas, los instrumentos e incluso los factores ambientales que determinan la fuerza militar, política y económica en el sistema. Por lo mismo, teóricamente es difícil llegar a una concepción unitaria del poder sin incurrir en proposiciones tautológicas (poder es estar en capacidad de, ergo, poder es poder).
} 
estrategia mancomunada para abordar los mencionados requerimientos del sistema en función de la maximización del influjo sistémico del conjunto de Estados Latinoamericanos.

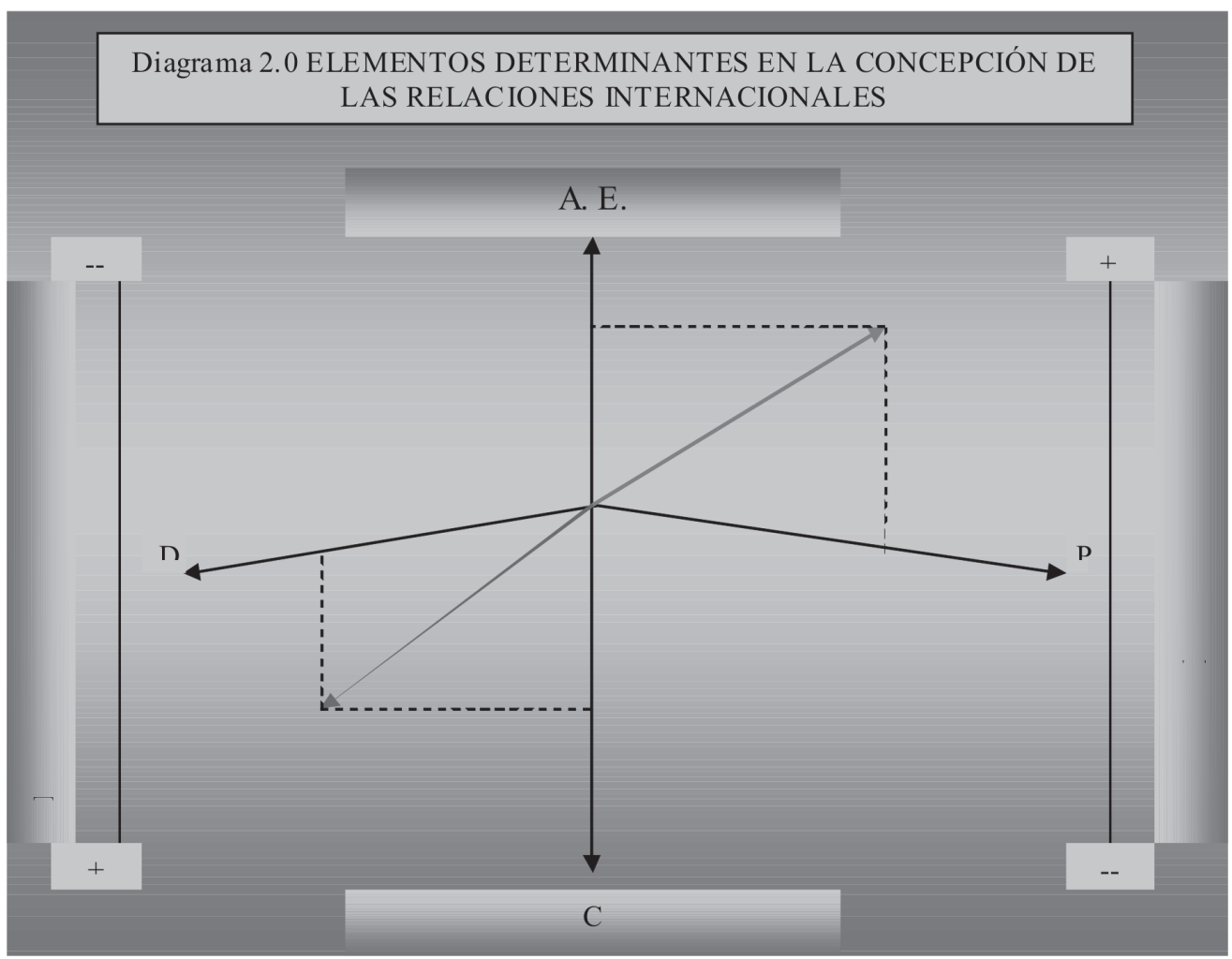

D: Desarrollo

P: Poder

A.E.: Alianzas Estratégicas

C: Cooperación

Latinoamérica

Occidente Desarrollado 
Propuesta para la configuración de un sentido comunitario eficiente.

Los procesos de construcción de la identidad, aquellos de base antropológica tanto como los de base sociológica, encuentran en la alteridad y la discusión por la naturaleza del otro un punto focal de sus supuestos.

Incluso en medio de las discusiones sobre Globalización, Universalismo y Cosmopolitismo, se recurre a las nociones de raza, etnia y nación política como punto de partida para guiar el proceso de construcción de los imaginarios colectivos de comunidad, que para ser llevados al conjunto de la sociedad internacional, se valen de la técnica y los recursos que evolucionaron en Occidente a partir de los procesos de industrialización y modernización.

Latinoamérica, fue entre los siglos XV y XVIII el escenario de la civilización (como proceso), entre el XVIII y mediados del XX el de la modernización y ahora el del desarrollo. Curiosamente, cada uno de estos procesos ha sido impulsado desde el exterior como un ideal para la vida en comunidad, a la vez que se incuban sentimientos de rechazo hacia el modelo y sus promotores por considerarlos restrictivos de la propia identidad.

El equívoco latinoamericano ha sido precisamente ese. La arraigada idea de que la identidad se contrapone a una dinámica política y económica impuesta por lo que supuestamente, el camino hacia la autodeterminación demanda la derrota de una lógica económica y de producción.

Tal ha sido el efecto devastador de esta idea, que regímenes personalistas de todas las corrientes han asumido la dirección de los Estados latinoamericanos sin que el anhelado bienestar llegue, dejando la puerta abierta a uno nuevo antagónico y eficiente únicamente como vector de transmisión en ese círculo vicioso.

Desestimar el papel de las elites políticas, en la implementación del modelo económico, a favor de la idea de un modelo perverso catastrófico en sí mismo para las economías en desarrollo, fue la falacia de los regímenes políticos del siglo XX, constituyendo el mayor estímulo para la irresponsabilidad política que los caracteriza ${ }^{38}$.

De acuerdo con el imaginario latinoamericano clásico, aquel que ha imperado de manera por demás ineficiente en las reivindicaciones relativas a la identidad comunitaria de la región, el autor del modelo, el otro, el extraño, es el artífice de una manipulación ideológica fundada en un poderío económico que subyuga la identidad de los pueblos, por lo que la construcción de

\footnotetext{
${ }^{38}$ CUERVO, Jorge Iván. El Ajuste Estructural, la Política y las Instituciones. El Caso Chileno y Conjeturas sobre Argentina. Universidad Externado de Colombia. Pp. 276.
} 
la identidad pasa por librarse de las cadenas impuestas por el tirano europeo, el gigante del norte o quien sea según el momento histórico la encarnación de los valores universales cuyos frutos anhela ${ }^{39}$, pero de los que no ha podido nutrirse la región ${ }^{40}$.

Cornelius Castoriadis, señala que casi todas las sociedades conocidas han acudido al proceso de "clausura del sentido", esa necesidad que tienen las sociedades así como las significaciones imaginarias de que son portadoras de clausurarse ante el mundo que las rodea.

Ello supone, continúa Castoriadis, que toda sociedad posee un exterior constitutivo que interviene en el proceso de creación de la identidad y que finalmente es lo que la hace posible. El exterior constitutivo latinoamericano, es tradicionalmente construido sobre la idea del actor foráneo, que si bien define unos estándares de bienestar que son aceptados y naturalizados, es a la vez el culpable de limitar el acceso a los recursos necesarios para acceder al bienestar, de donde emerge la idea de emancipación necesaria en el camino a la constitución de la propia identidad.

Como ejemplo, podemos remitirnos al momento en que las ideas de Heinz Dietrich, sociólogo alemán fundador del «socialismo siglo XXl», fueron adoptadas como marco ideológico para promover el regionalismo desde Venezuela. Cuando el régimen de ese país acudió al supuesto antropológico propuesto por Castoriadis de que las fronteras, los territorios y los «otros», adquieren importancia en función de los sentidos específicos que los miembros y las instituciones de una sociedad específica les atribuyen.

Entonces, como institución y responsable de la ejecución del proyecto de regionalización, el gobierno venezolano debería estar en capacidad de comunicar a las unidades que componen la región los sentidos específicos que deben atribuirse a los antagonistas.

\footnotetext{
${ }^{39}$ Basta con observar como la lucha por la emancipación culminó con la euforia por la ejecución del mismo modelo social e institucional ibérico en manos de élites locales; o como las políticas «revolucionarias» en materia económica y productiva del siglo XXI son una copia tardía del Estado benefactor concebido en el New Deal.

${ }^{40}$ Tal concepción es claramente errada considerando que implica caer en las etapas modernizantes de corte estadounidense, ignorando la interdependencia y se cae en un discurso latinoamericanista anti-modernizante.
} 


\section{Diagrama 3.0 Modelo Exterior Constructivo ${ }^{41}$.}
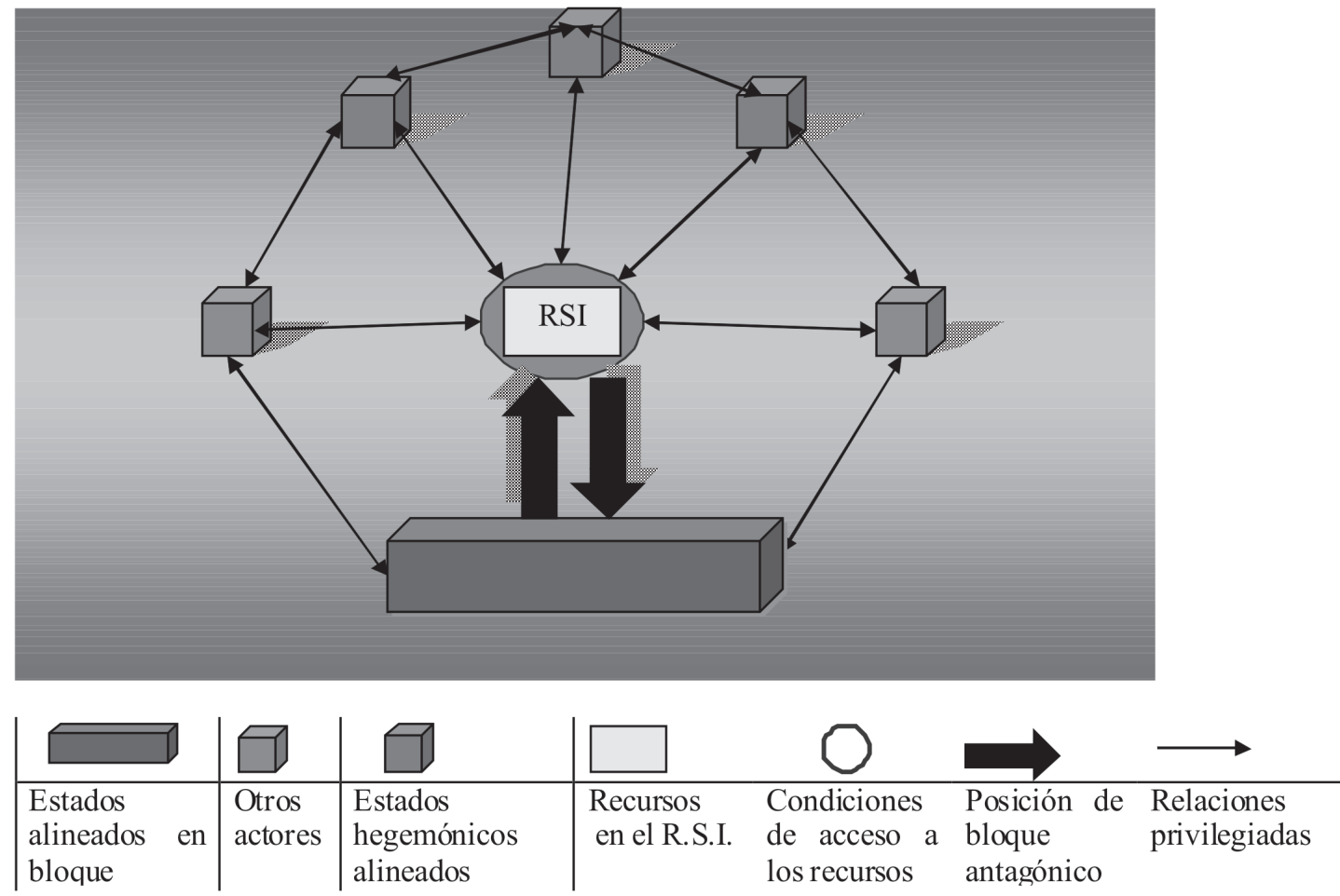

Sin embargo, esta suerte de «regionalismo particularista», ${ }^{42}$ a la que corresponde el así llamado «Movimiento Bolivariano», no es clara al momento de definir los límites a partir de los cuales se

\footnotetext{
${ }^{41}$ De acuerdo con este modelo, las afinidades entre los Estados alineados deben ser suficientes para asumir una posición de bloque fundada en una diferencia excluyente que afecta las relaciones con otros Estados, permitiendo la interrelación dinámica con algunos pero limitándola con aquellos considerados antagónicos. Las dificultades de este modelo para orientar las relaciones internacionales y la política exterior del Estado son evidentes: Primero, no describe la realidad internacional de forma acertada por cuanto aún con los Estados considerados teóricamente antagónicos, se dan interacciones de algún tipo (generalmente económico), segundo, se pretende acceder a los recursos del sistema en una lógica de choque que no da muchas certezas respecto a las posibilidades de éxito y, tercero, se pretende que uno solo de los rasgos característicos del Estado (aquel que es compartido) se sobreponga a los demás como criterio de definición de la política exterior.

${ }^{42}$ De acuerdo a la categorización propuesta por Hettne, el regionalismo particularista implica una agresividad potencial hacia otras regiones, siendo una versión del nacionalismo extendido. Sin embargo, el movimiento bolivariano no puede considerarse como nacionalismo extendido por cuanto carece de la espontaneidad que este requiere para su configuración, de lo que se obtiene que a la luz del planteamiento del autor el regionalismo lanzado desde Venezuela es una versión de regionalismo hegemónico particularista. Ver: HETTNE, Bjorn. Global Market Versus Regionalism. En: HELD, David y McGREW, Anthony. The Global Transformations Reader, An Introduction to the Globalization Debate. Polity Press. Cornwall UK. 2000. pp. 156- 166.
} 
construye la identidad del grupo dado que, con cargo a la oposición imaginaria entre autodeterminación y lógica económica, existen Estados que a la luz del discurso son parte del grupo mientras que por su alineación y formas económicas le son extraños, como es el caso de Colombia.

El afán de situar el exterior constitutivo de la región en una lógica económica y el acudir a una herencia histórica compartida como significación social imaginaria de comunidad, se han mostrado incompatibles y por consiguiente, el proceso de construcción de identidad colectiva en este modelo queda viciado para articularse como parte de una estrategia política comunitaria practicable ${ }^{43}$.

La propuesta aquí, es remplazar el modelo de exterior constitutivo por uno de interior constructivo, que se apoye en los hábitos informales y en los elementos civilizacionales ${ }^{44}$ propios de Latinoamérica, como base para la construcción de instituciones formales que gocen de legitimidad frente a los ciudadanos de cada Estado.

Los vínculos lingüístico, étnico y cultural, si bien son insuficientes para constituir la base formal de una organización política regional, pueden ser la base informal de una idea de comunidad. Como señalaba Alexis de Tocqueville en su obra «La democracia en América», el régimen estadounidense estaba cimentado en una idea de igualdad que definía las instituciones políticas mientras que impregnaba el comportamiento y las creencias de sus ciudadanos de tal forma que los hábitos informales, esas capas sociológicas y antropológicas de la vida política ${ }^{45}$, sostenían y posibilitaban las instituciones políticas formales.

Un paso ineludible hacia la definición de una identidad colectiva en el modelo de interior constructivo propuesto es el abandono del supuesto marxista y neoliberal de que lo económico determina lo político. Más que una variable endógena del modelo económico, lo político es su contexto determinante y las instituciones políticas su referente normativo.

\footnotetext{
${ }^{43}$ En la actualidad, los esfuerzos por construir una política regional latinoamericana con base en aspectos particulares de su historia común son obstaculizados por una contradicción inherente a ellos: El pasado común latinoamericano está dado también por la adopción de ciertos conceptos férreamente adheridos al imaginario colectivo de sus sociedades, como lo es el de la nacionalidad vinculada al Estado Territorial.

${ }^{44}$ Como lo señala Braudel, «a cada época corresponde una determinada concepción del mundo y de las cosas. Una mentalidad colectiva predominante que anima y penetra a la masa global de la sociedad. Esta mentalidad que determina las actitudes y las decisiones, arraiga los prejuicios, influye en un sentido o en otro los movimientos de una sociedad, es eminentemente un factor de civilización.» BRAUDEL, Fernand. las Civilizaciones Actuales, Estudio de Historia Económica y Social». Editorial Tecnos S.A. 1983. pp. 32.
}

${ }^{45}$ FUKUYAMA, Francis. «América en la Encrucijada. Democracia, Poder y Herencia Neoconservadora». Ediciones B. S.A., 2007. pp. 38 - 39. 
El modelo propuesto parte del desconocimiento de la premisa clásica de que el Estado en sus Relaciones Internacionales actúa como una caja negra. Al interior de él, existen actores colectivos e individuales que pueden ser sujetos de interacción en el sistema y que mediante mecanismos institucionales domésticos, pueden llevar sus demandas al plano internacional en procura de la satisfacción de sus necesidades; bien sea por acción directa de los Estados a los que se encuentran asociados o mediante la veeduría de actores de diferente naturaleza.

Además, la eficiencia institucional permitiría que los valores tradicionales compartidos por esos colectivos contenidos en diferentes Estados, tengan una mayor comunicación en el plano internacional, nutriéndose de su dinámica y ganando de esta forma mayor coherencia entre sus supuestos y aquella; proceso que favorece las posibilidades de articular los valores colectivos con la política exterior de los Estados en una dinámica comunitaria.

La distancia entre este modelo y la propuesta de Alexander Wendt ${ }^{46}$, está dada por la creencia de que las instituciones son más que simples factores causales importantes para la política exterior. Más bien, alejándose del supuesto institucionalista de la practica, autonomía de las instituciones, ellas son mecanismos de comunicación social por la cual los colectivos interactúan de forma organizada (como sociedad civil) con el Estado al cual se hallan asociados, con otros actores internacionales y con otros colectivos con valores compartidos en procura de orientar en su favor las acciones de los órganos ejecutivos correspondientes.

Fukuyama señala a propósito del pensamiento de Tocqueville que aquel «dedicó mucho tiempo a explicar por qué la democracia funcionaba mejor en Estados Unidos que en su Francia natal, basándose en la existencia de lo que hoy en día llamamos «estructuras de apoyo» en los ámbitos de la cultura y la práctica social» ${ }^{47}$.

${ }^{46}$ WENDT, Alexander. Social Theory of International Politics. Cambridge: Cambridge University Press. 1999.

${ }^{47}$ Ibíd. Pp. 43 
Diagrama 4.0 Modelo propuesto de Interior Constructivo

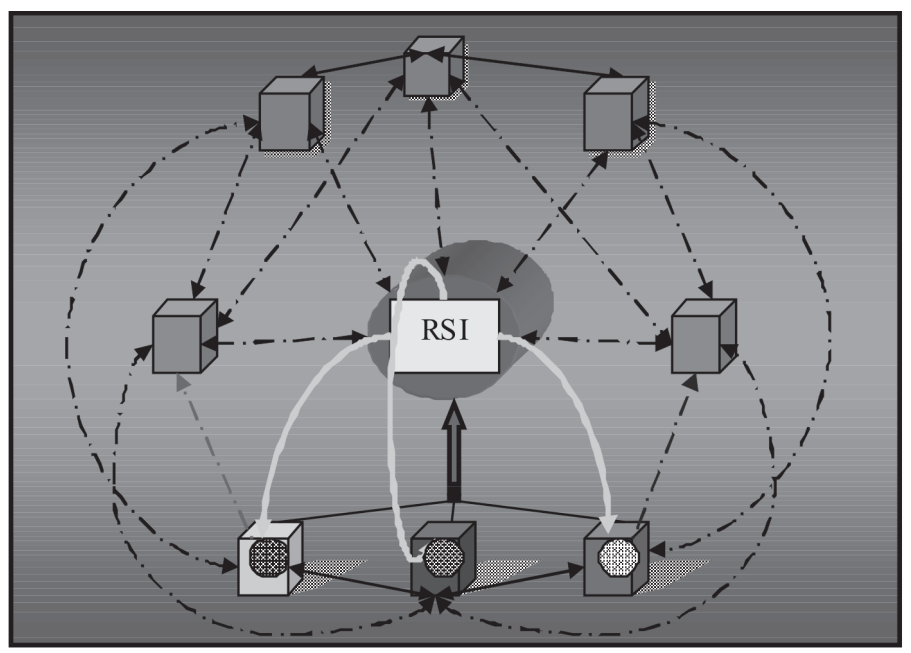

\begin{tabular}{llll|}
$\begin{array}{l}\text { Otros Estados } \\
\text { Alineados }\end{array}$ & $\begin{array}{c}\text { Otros Actores } \\
\text { Internacionales }\end{array}$ & $\begin{array}{c}\text { Estados Afines } \\
\text { (Latinoamericanos) }\end{array}$ \\
\hline $\begin{array}{l}\text { Interaccion no } \\
\text { exclusiva entre } \\
\text { actores no estatales }\end{array}$ & $\begin{array}{l}\text { Interaccion no } \\
\text { exclusiva entre } \\
\text { actores estatales }\end{array}$ & $\begin{array}{c}\text { Condiciones de acceso a } \\
\text { los recursos del Sistema }\end{array}$ & $\begin{array}{c}\text { Recursos del } \\
\text { Sistema } \\
\text { Internacional }\end{array}$ \\
$\begin{array}{l}\text { Interacción } \\
\text { preferencial } \\
\text { (Alianzas) }\end{array}$ & Recursos obtenidos del Sistema & Acción internacional coordinada \\
+ influjo sistémico de O
\end{tabular}

El argumento en la propuesta del interior constructivo, es que los vínculos étnicos, lingüísticos e históricos que erradamente se han invocado como eje de una política comunitaria enmarcada en una lógica económica particular, deben ser concebidos más bien como las estructuras de apoyo sobre las cuales en el curso del diálogo político entre las instituciones, las soluciones en materia de política exterior adoptadas por cada Estado para salvar la distancia entre las necesidades de sus ciudadanos y los recursos del Sistema, se verían coordinadas. 
Al final de este proceso, se estaría en presencia de una acción política internacional diferenciada más no contradictoria, que se solidifica a medida que los Estados tratan de solucionar por los canales comunitarios, una porción mayor de las necesidades de sus ciudadanos, quienes con el tiempo, van produciendo nuevas significaciones que se proyectan mediante la socialización desde un sentido inicial coextensivo a su propia esfera psíquica privada, a un sentido social común ${ }^{48}$.

Si, como se demostró, los vínculos más exclusivos de las sociedades actuales como la nacionalidad son de carácter contractual, consensual y constructivo; y la etnicidad y la raza, a diferencia de lo que sucede en otras regiones como los Balcanes y África, son poco relevantes como factor político en Latinoamérica, es válido suponer que al ser las instituciones políticas (formales e informales) ${ }^{49}$ integradas, transformadas y conservadas por individuos interactuantes, puede darse de manera constructiva, de adentro hacia fuera, la instauración de nuevos valores identitarios, que se nutran de los antiguos, y que deriven en la práctica de acciones políticas comunitarias.

\section{BIBLIOGRAFÍA}

- $\quad$ ANSALDI, Waldo. La Temporalidad Mixta de América Latina. Una Expresión de Multiculturalismo. En: SILVEIRA, Héctor (editor). Identidades Comunitarias y Democracia. Editorial Trotta. Madrid. 2000 .

- ARROYO, Graciela. «Metodología de las RRIl». Oxford University Press. 1999

- $\quad$ BALIBAR, Etiene y WALLERSTEIN, Immanuel. Razza, Nazione, Classe. Le identitá ambigue. 1990.

- BERTRAND, Badie. Análisis comparativo y sociología histórica, Revue Internationale des Sciences Sociales, UNESCO, número 133. Paris. Agosto de 1992.

- BRAUDEL, Fernand. «Las civilizaciones actuales, estudio de historia económica y social» Tecnos S.A. 1983

${ }^{48}$ SILVEIRA, Héctor. «La vida en común en las sociedades multiculturales». Recopilado en : SILVEIRA, Hector (editor). Identidades Comunitarias y Democracia. Editorial Trotta. Madrid. 2000.

${ }^{49}$ Vale la pena resaltar los comentarios del filólogo y filósofo francés Ernest Renán quien señala que «las instituciones son como los aros del tonel que determinan la capacidad interna de un recipiente duradero. Y de todas las instituciones, la más vivaz es la lengua [...] La lengua, la religión, las leyes, las costumbres, hicieron de la raza mucho más que la sangre». RENAN, Ernest. Historia del pueblo de Israel. Editorial Iberia, Madrid. 1947 - 1961. pp. 32. 
- CARRILLO, Fernando (ed.) Democracia en Déficit. Gobernabilidad y Desarrollo en América Latina y el Caribe, Washington, BID, 2001.

- CAVARROZZI, Marcelo. Partidos Políticos, Desestatización y Reforma Estructural: ¿El Retorno de la Política en América Latina? En: CARRILLO, Fernando (ed.) Democracia en Déficit. Gobernabilidad y Desarrollo en América Latina y el Caribe, Washington, BID, 2001.

- Córdova, Armando. «Crisis económica mundial y futuro de América Latina». En: Pensamiento Crítico: Un diálogo Interregional 2. «Universalismo y Desarrollo. Lander/Sonntag Editores. UNESCO, Rectorado Universidad Central de Venezuela. Ed. Nueva Sociedad. 1991.

- CUERVO, Jorge Iván. El Ajuste Estructural, la Política y las Instituciones. El Caso Chileno y Conjeturas sobre Argentina. Universidad Externado de Colombia. 2007.

- FUKUYAMA, Francis. «América en la Encrucijada. Democracia, Poder y Herencia Neoconservadora». Ediciones B. S.A., 2007.

- GÁMEZ, Alba E. «Regionalización y Globalización: Los países en desarrollo en la política económica internacional de la posguerra fría». Aportes, Revista Facultad de Economía - BUAP. Año VIII, num. 22

- HELD, David. Transformaciones globales, México. Oxford. 2002.

- HETTNE, Bjorn. Global Market Versus Regionalism. En: HELD, David y McGREW, Anthony. The Global Transformations Reader, An Introduction to the Globalization Debate. Polity Press. Cornwall UK. 2000.

- HOBSBAWM, Eric. Años interesantes, Una vida en el siglo XXI. Editorial Crítica. Barcelona, 2003. pp. 345.

- HOBSBAWM, Eric. Identidad. Recopilado en: GORSKI, Héctor (editor). Identidades Comunitarias y Democracia. Editorial Trotta. Madrid. 2000.

- HOBSBAWM, Eric y RANGER, Terence. L'invenzione della Tradizzione, Torino. 1991

- IACONO, Alfonso. Raza, Nación, Pueblo: Caras Ocultas del Universalismo. En: SILVEIRA, Hector (editor). Identidades Comunitarias y Democracia. Editorial Trotta. Madrid. 2000.

- KEOHANE, Robert O. Poder e Interdependencia. Ed. GEL. Buenos Aires. 1988.

- KEOHANE, Robert y NYE, Joseph. Poder e interdependencia: la política mundial en transición. Buenos Aires: Grupo Editor Latinoamericano. 1988.

- KUHN, Thomas. «The Structure of Scientific Revolutions». Chicago and London: University of Chicago Press. 1970.

- MORGENTHAU, Hans J. Política entre las naciones: la lucha por el poder y la paz. Buenos Aires: Grupo Editor Latinoamericano, 1986. 
REVISTA - Bogotá (Colombia) Vol. 3 No. 2 - Julio - Diciembre

- SILVEIRA, Héctor. «La vida en común en las sociedades multiculturales». Recopilado en: SILVEIRA, Héctor (editor). Identidades Comunitarias y Democracia. Editorial Trotta. Madrid. 2000.

- WALLERSTEIN, Immanuel. El Capitalismo Histórico, Editorial Siglo XXI. México, 1988.

- WENDT, Alexander. Social Theory of International Politics. Cambridge: Cambridge University Press. 1999.

- CEPAL-BID. Regímenes competitivos sectoriales, productividad y competitividad internacional. Santiago de Chile, Marzo 15 de 2001.

LAUE, Theodore Von. «The World revolution of westernization. The twentieth century in global perspective». Oxford University press. New York, 1987. 